\title{
Investigation on the Behavior of Tensile Damage Evolution in T700/6808 Composite Based on Acoustic Emission Technology
}

\author{
Weihan Wang, Weifang Zhang, Shengwang Liu, and Xiaoshuai Jin \\ Science \& Technology on Reliability \& Environmental Engineering Laboratory, Beihang University, Beijing 100191, China \\ Correspondence should be addressed to Weifang Zhang; 08590@buaa.edu.cn
}

Received 24 March 2016; Revised 16 May 2016; Accepted 24 May 2016

Academic Editor: Samuel da Silva

Copyright (C) 2016 Weihan Wang et al. This is an open access article distributed under the Creative Commons Attribution License, which permits unrestricted use, distribution, and reproduction in any medium, provided the original work is properly cited.

\begin{abstract}
T700/6808 composite has been widely used in aerospace field and the damage in composite will seriously influence the safety of aircraft. However, the behavior of damage evolution in T700/6808 composite when it suffered from tensile loading is seldom researched. In this paper, the acoustic emission (AE) technology is employed to research the process of damage evolution in T700/6808 composite under tensile loading. Results show that the damage in T700/6808 composite is small in the initial stage of tensile loading, and main damage is the matrix cracking. The composite has serious damage in the middle stage of tensile loading, which mainly includes the matrix cracking and the interface damage as well as the fiber breakage. The number of fiber breakages decreases rapidly in the later stage of tensile loading. When it comes into the stage of load holding, the composite has relatively smaller damage than that in the stage of tensile loading, and the fiber breakage rarely occurs in the composite. Analysis of damage modes shows that the criticality of the matrix cracking and the interface damage is higher than the fiber breakage, which illustrates that the reliability of T700/6808 composite could be improved by the optimization of matrix and interface.
\end{abstract}

\section{Introduction}

T700/6808 composite is a new kind of carbon fiber reinforced epoxy resin matrix composite, which has been widely used in the aircraft structure for its excellent properties, such as light weight, high specific strength, and well resistance to the fatigue fracture $[1,2]$. During the manufacturing and flight process of structure, damage would occur in the T700/6808 composite which will influence the structural safety of aircraft.

At present, detection methods for the composite mainly include the visual method, X-ray method, and ultrasonic testing method. Acoustic emission (AE) technology is a kind of nondestructive detection method, which could be used for detecting the defect or the damage in composite, such as container leakage, blade damage, and wing crack detection [3-5]. In the past few decades, the AE research has obtained attentions from scholars. Chou et al. [6] used the AE method to detect the damage in carbon fiber composite pressure vessel. Al-Jumaili et al. [7] presented an AE parameter correction method which could be used for the damage detection in large composite component. Maillet et al. [8] proposed an AE detection method with double sensors, which could evaluate the energy attenuation of damage process in composite structure. Saeedifar et al. [9] used AE method for detecting the delamination damage in glass reinforced epoxy resin composite. Liu and Xia [10] applied AE system to detect the fatigue damage in composite blades. Masmoudi et al. [11] combined AE method with piezoelectric technology to detect the damage in composite sandwich structures.

Despite several advancements reported on the $\mathrm{AE}$ research, however, little published works have been focused on the damage monitoring in T700/6808 composite, and its damage evolution behavior remains unclear. At present, researchers mainly focused on the mechanical property analysis of T700 series composite. Zhou et al. [12] developed a method to characterize the fatigue strength distribution of T700 carbon fibers by fiber bundles testing. Zhang et al. [13] researched the difference of mechanical properties between two kinds of T700 composite, which shows that the fiber defect may lead to the property difference. Wang et al. [14] carried out the tension-tension fatigue test on T700/9368 composite laminate and explored the damage mechanism by ultrasonic C-scan. Chiu et al. [15] investigated the behavior 

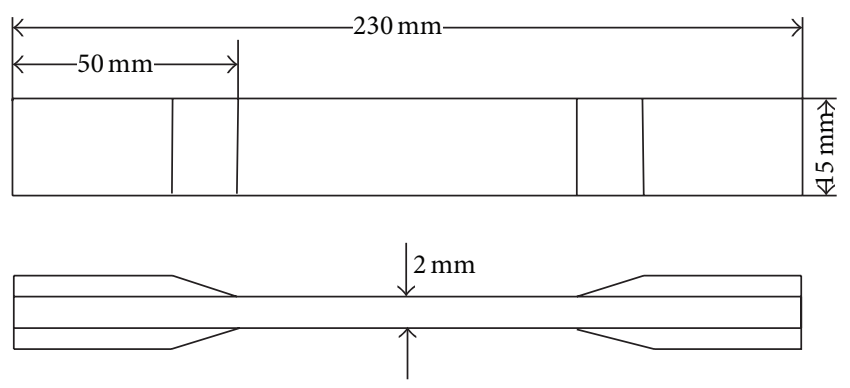

FIGURE 1: Schematic diagram of the specimen.

of T700/M21 composite energy absorber under static and dynamic loading, and the consistent damage modes and measured force responses were obtained.

In order to obtain the behavior of damage evolution in T700/6808 composite and discover the weakness of the material, the tensile testing and acoustic emission technology were used to analyze the T700/6808 composite in the paper. The damage behavior of T700/6808 composite under tensile loading, as well as the weakness in composite, could be obtained and the result provides the basis for the optimization and improvement of the material.

\section{Materials and Methods}

2.1. Specimen Preparation. Tensile specimens were designed according to the national standards GB/T 3354-1999 [16] and three specimens had been prepared in the experiment. Detailed geometry of the specimen is shown in Figure 1. The specimen is made of T700/6808 carbon fiber reinforced epoxy resin matrix composite, and the composite is unidirectional ply.

2.2. Experiment Design. The experiment platform is shown in Figure 2. The platform consisted of a tensile testing machine and a set of $\mathrm{AE}$ system. The room temperature is $27^{\circ} \mathrm{C} \pm$ $2^{\circ} \mathrm{C}$. During the tensile testing, the AE system was employed to record the damage signal from the T700/6808 composite. Tensile testing for the specimen was conducted on WDW300 tensile testing machine as shown in Figure 2(a), and the loading rate was set as $50 \mathrm{~N} / \mathrm{s}$ and the maximum load was set as $40 \mathrm{KN}$. When the tensile load reaches $35 \mathrm{KN}$, the system automatically enters into the state of load holding for 24 hours. The AE system is MISTRA 2001 E1.12 which is made from Physical Acoustics Corporation. The information of PAC-WSa sensor is shown as follows. (1) As shown in Figure 2(b), the AE sensor is pasted on the middle of the specimen with vacuum grease and it is fixed with elastic for well contact. (2) The detection frequency is $0-551.36 \mathrm{KHz}$. (3) The preamp gain is $40 \mathrm{~dB}$. (4) The sampling rate is 1 MSPS.

\section{Results}

3.1. AE Signal Analysis of T700/6808 Composite under Tensile Loading. Three specimens were used in the experiment, and it is found that the damage behavior and the change trend of
AE signal are similar among three specimens during tensile testing; therefore, the specimen of number 1 is studied in detail. The change of AE hit number with the tensile loading time is shown in Figure 3.

As shown in Figure 3(a), in the initial stage of tensile loading $(0-60 \mathrm{~s})$, the AE hit number is mainly distributed in the interval between 0 and 20. When it comes into the middle stage of tensile loading from $60 \mathrm{~s}$, the AE hit number suddenly increases to about 85 . In the middle stage of tensile loading (60-580 s), the value of $\mathrm{AE}$ hit number relatively maintains a high level, such as 132 at 125 s, 138 at 220 s, and 107 at 520 s. It indicates that, in the middle stage of tensile loading, the composite suffered severe damage which led to the occurrence of large quantity of AE hit number. From $580 \mathrm{~s}$, when it comes into the later stage of tensile loading, the value of $\mathrm{AE}$ hit number begins to decrease. The minimum $\mathrm{AE}$ hit number is 17 when the testing time is close to $700 \mathrm{~s}$, which indicates that the damage in composite was small in the later stage of tensile loading (580-700 s).

From $700 \mathrm{~s}$, the tensile system automatically enters into the stage of load holding. From final phase of Figure 3(a), it can be seen that the value of AE hit number mainly stays under 25 in the initial stage of tensile loading (700-1000 s). In Figure 3(b), most of the AE hit number stays under 20 in the middle stage of load holding (1000-10000 s), except for 118 at 1800 s. In Figure 3(c), the AE hit number still remains little in the later stage of load holding (10000-80000 s); however, the quantity of AE hit number is more than that in the middle stage of load holding.

The change of AE hit amplitude with the tensile loading time is shown in Figure 4.

As shown in Figure 4(a), most of AE signal is distributed between $55 \mathrm{~dB}$ and $70 \mathrm{~dB}$ from $0 \mathrm{~s}$ to $60 \mathrm{~s}$; however, none of $\mathrm{AE}$ signal is distributed between $70 \mathrm{~dB}$ and $100 \mathrm{~dB}$. From $60 \mathrm{~s}$ to $580 \mathrm{~s}$, the AE signal is mainly distributed between $55 \mathrm{~dB}$ and $100 \mathrm{~dB}$. Among them, the number of AE signals which is distributed between $55 \mathrm{~dB}$ and $60 \mathrm{~dB}$ is the most, and the number of $\mathrm{AE}$ signals which is distributed between $70 \mathrm{~dB}$ and $100 \mathrm{~dB}$ is the least. From $580 \mathrm{~s}$, the number of AE signals begins to decrease and the AE signal distributed between $60 \mathrm{~dB}$ and $100 \mathrm{~dB}$ reduces the fastest. From $700 \mathrm{~s}$ to $1000 \mathrm{~s}$, the AE signal is mainly distributed between $55 \mathrm{~dB}$ and $60 \mathrm{~dB}$ and little signal is distributed between $60 \mathrm{~dB}$ and $70 \mathrm{~dB}$; meanwhile, none of signal is distributed between $70 \mathrm{~dB}$ and $100 \mathrm{~dB}$.

As shown in Figure 4(b), from $1000 \mathrm{~s}$ to $10000 \mathrm{~s}$, the AE signal is mainly distributed between $55 \mathrm{~dB}$ and $60 \mathrm{~dB}$, and the following is the AE signal which is distributed between $60 \mathrm{~dB}$ and $70 \mathrm{~dB}$. However, the number of AE signals which is distributed between $70 \mathrm{~dB}$ and $100 \mathrm{~dB}$ is the least. From Figure 4(c), it can be seen that the distribution of AE signal from $10000 \mathrm{~s}$ to $80000 \mathrm{~s}$ is similar to the distribution from $1000 \mathrm{~s}$ to $10000 \mathrm{~s}$.

3.2. Damage Evolution Analysis in T700/6808 Composite. In order to obtain the damage characteristic in T700/6808 composite during tensile testing, a preparation experiment used to establish the relationship between the damage modes and AE signal had been conducted before the formal tensile 


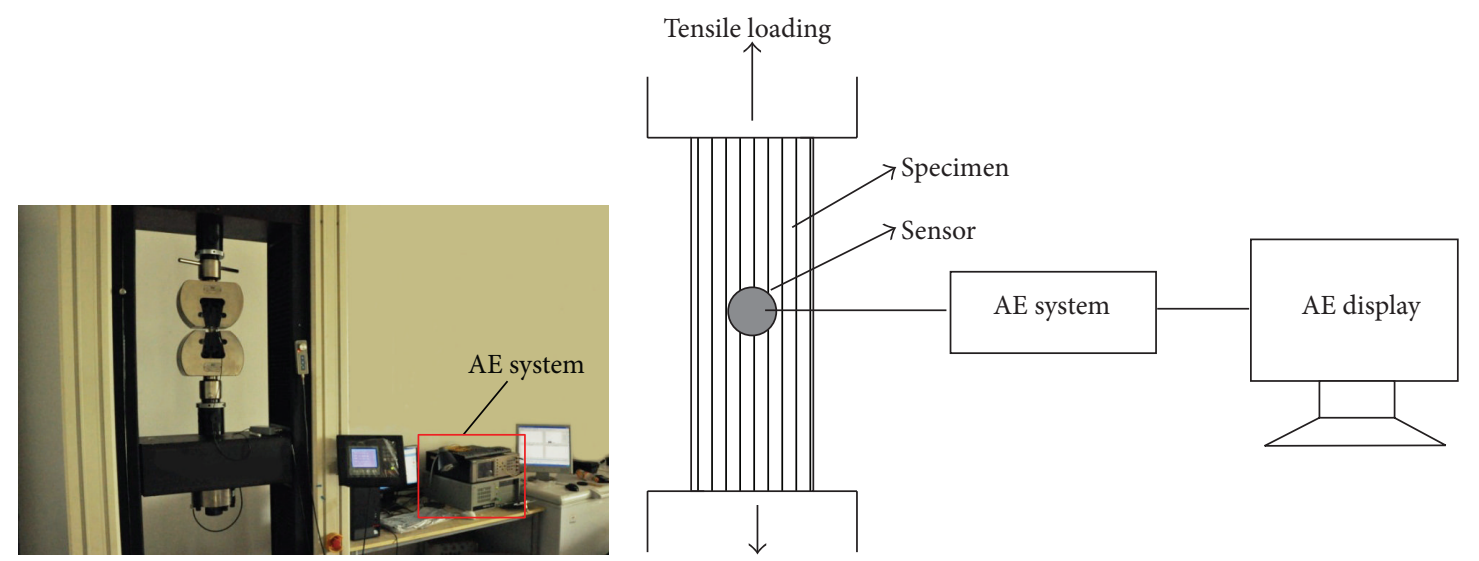

(a)

(b)

FIGURE 2: Experiment platform. (a) Experimental equipment; (b) diagram of equipment connection.

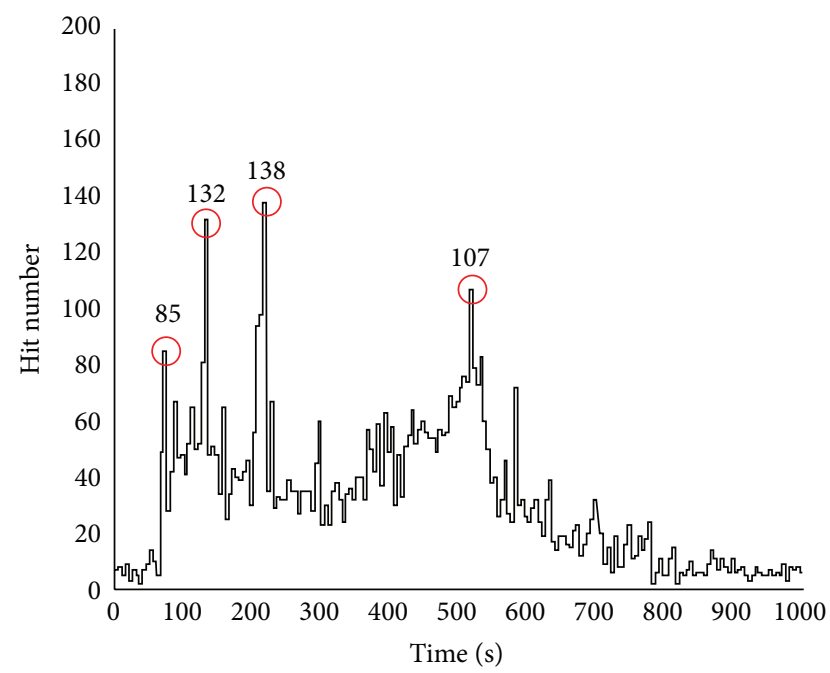

(a)

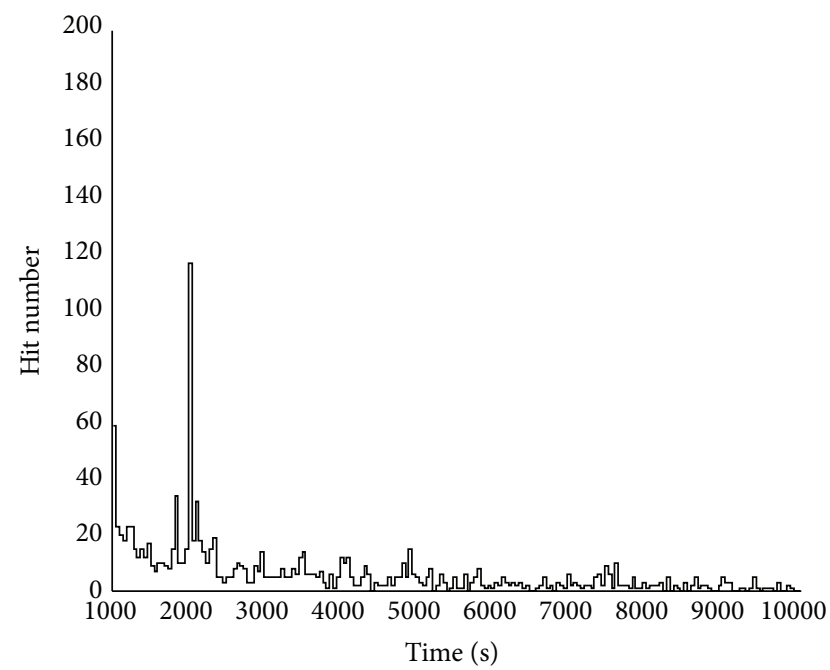

(b)

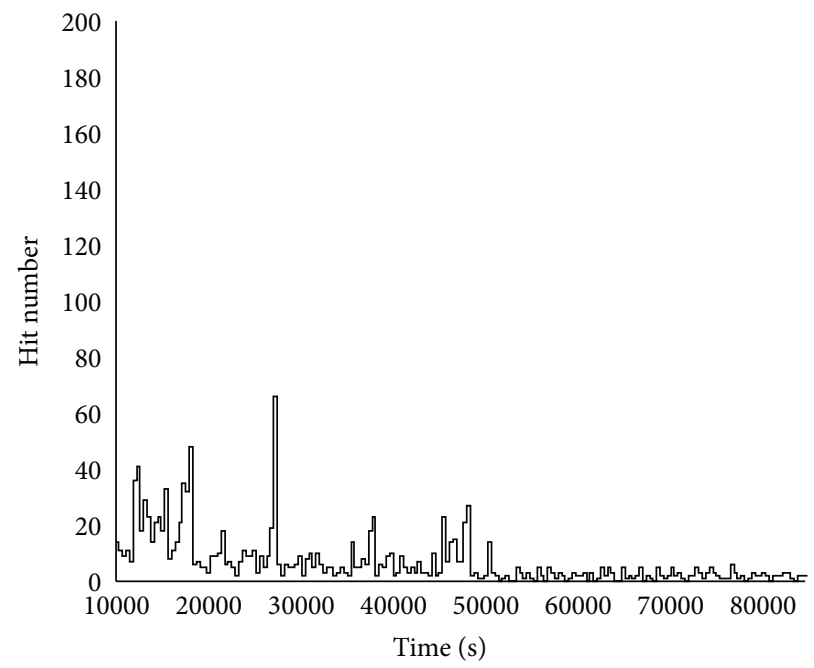

(c)

FIgUre 3: Change of AE hit number with the tensile loading time: (a) $0 \mathrm{~s}-1000 \mathrm{~s}$; (b) $1000 \mathrm{~s}-10000 \mathrm{~s}$; (c) $10000 \mathrm{~s}-80000 \mathrm{~s}$. 


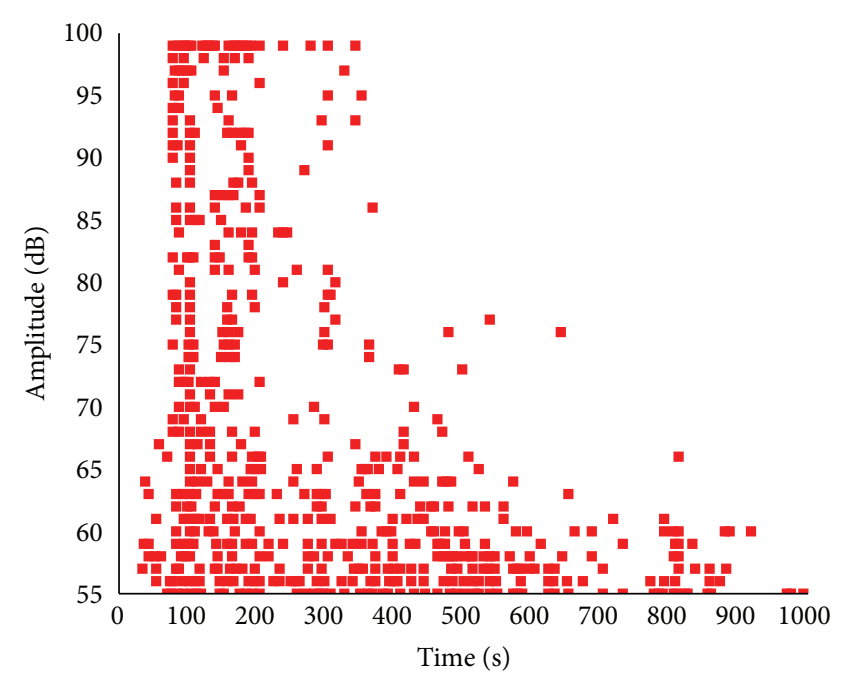

(a)

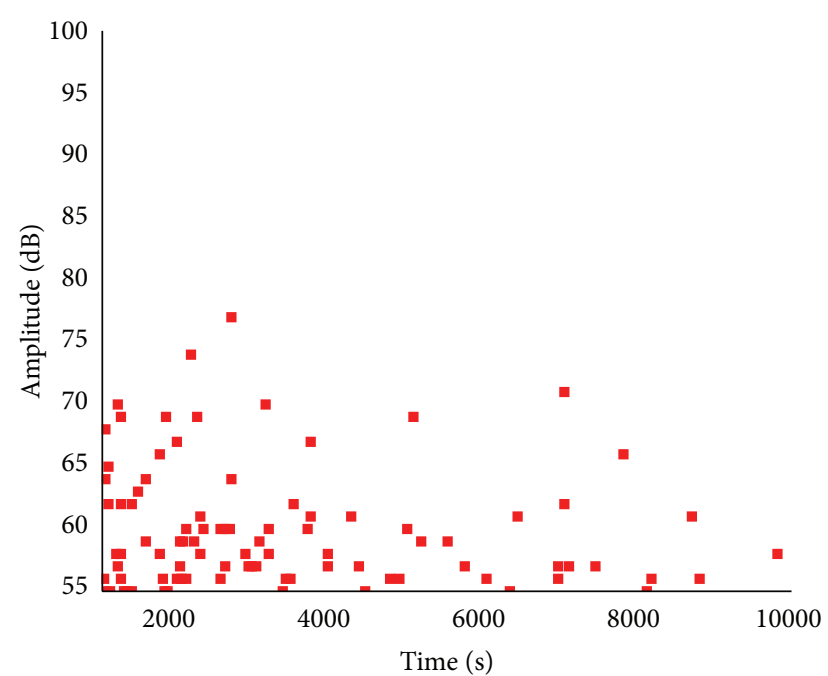

(b)

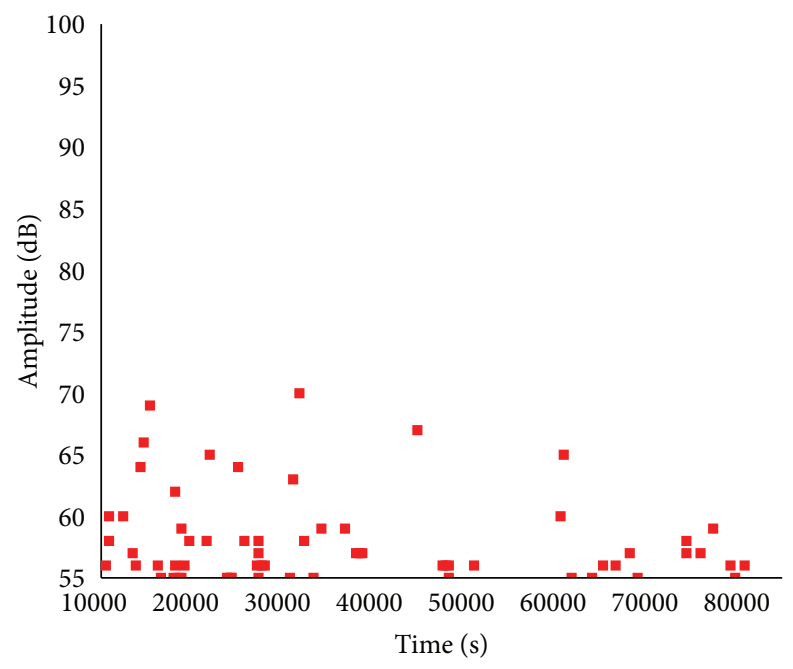

(c)

FIGURE 4: Change of AE hit amplitude with the tensile loading time: (a) 0 s-1000 s; (b) 1000 s-10000 s; (c) 10000 s-80000 s.

testing. Several specimens were prepared and the method of material microscopic analysis was used in the experiment.

During the experiment, the specimen was taken off the tensile testing machine as needed according to the variation of AE amplitude. Damage morphology could be observed under microscope and electron microscope. Based on the repeated testing and observation, and other references [1719] being learned also, the relationship between $\mathrm{AE}$ signal and damage mode in T700/6808 composite could be established.

From the preparation experiment, it is found that the matrix cracking had occurred when the AE amplitude reached $55 \mathrm{~dB}$, and the micromorphology is shown in Figure 5 .

As tensile loading time increases, the value of $\mathrm{AE}$ amplitude also increased. When the value of $\mathrm{AE}$ amplitude reached $60 \mathrm{~dB}$, the interface damage occurred in the specimen, and the micromorphology is shown in Figure 6(a). When the value of $\mathrm{AE}$ amplitude came into $70 \mathrm{~dB}$, the fiber breakage could be observed in the specimen as shown in Figure 6(b).

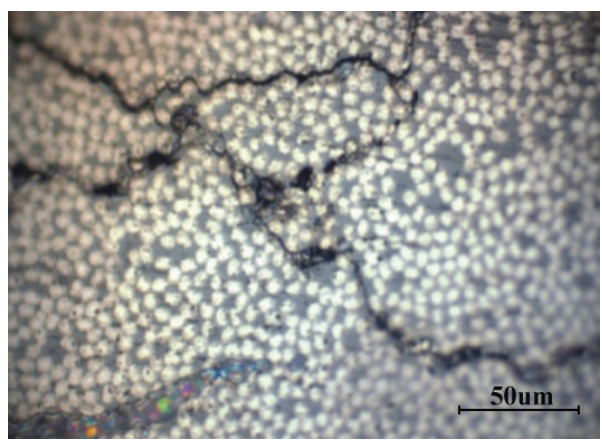

FIGURE 5: Micromorphology of matrix cracking in T700/6808 composite (AE amplitude $\geq 55 \mathrm{~dB}$ and $\leq 60 \mathrm{~dB}$ ).

From Figure 6(a), it could be observed that the interface damage with parallel linear form occurred in the specimen. In Figure 6(b), large area of fiber breakage could be observed 


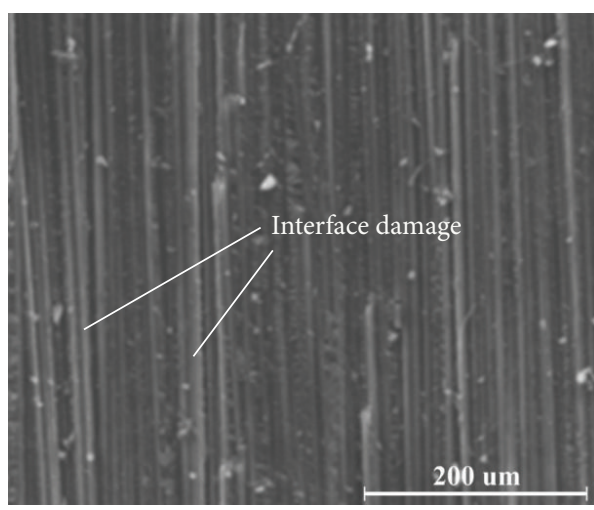

(a)

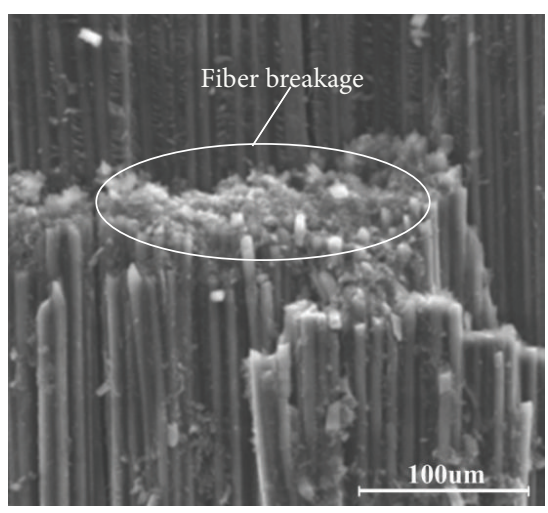

(b)

Figure 6: Micromorphology of damage modes in tensile specimen: (a) interface damage (AE amplitude $\geq 60 \mathrm{~dB}$ and $\leq 70 \mathrm{~dB}$ ); (b) fiber breakage (AE amplitude $\geq 70 \mathrm{~dB}$ and $\leq 100 \mathrm{~dB}$ ).

clearly in the specimen and a small amount of interface damage appears in the distance. Consequently, the $\mathrm{AE}$ amplitude corresponding to the damage mode in T700/6808 composite could be defined as follows: (1) $55 \mathrm{~dB}-60 \mathrm{~dB}$ is matrix cracking; (2) $60 \mathrm{~dB}-70 \mathrm{~dB}$ is interface damage; (3) $70 \mathrm{~dB}-100 \mathrm{~dB}$ is fiber breakage.

It could be obtained from Section 3.1, in the initial stage of tensile loading (0-60 s), the number of AE signals is little and the $\mathrm{AE}$ amplitude is low. It indicates that the damage in T700/6808 composite is small in this period, and a small amount of matrix cracking occurs. In the middle stage of tensile loading (60-580 s), the number of AE signals increases and the maximum value reaches $220 \mathrm{~s}$. The range of $\mathrm{AE}$ amplitude is $55 \mathrm{~dB}-100 \mathrm{~dB}$; however, the number of $\mathrm{AE}$ signals above $70 \mathrm{~dB}$ is significantly less than the number of signals below $70 \mathrm{~dB}$. From the distribution of damage modes, it is known that the major damage is matrix cracking, the secondary damage is interface damage, and the number of fiber breakages is the least. In the later stage of tensile loading (580-700 s), the number of AE signals decreases quickly. The range of $\mathrm{AE}$ amplitude is $55-70 \mathrm{~dB}$, and high amplitude signals almost no longer appear. The number of signals distributed between $55 \mathrm{~dB}$ and $60 \mathrm{~dB}$ is more than that of signals distributed between $60 \mathrm{~dB}$ and $70 \mathrm{~dB}$. It indicates that the matrix cracking and interface damage are the major damage in the later stage of tensile loading; however, the number of fiber breakages decreases rapidly for the reduction of the load.

When it comes into the initial stage of load holding (700$1000 \mathrm{~s}$ ), the incidence of $\mathrm{AE}$ signal reduces to the minimum. The signal is mainly distributed in the $55-60 \mathrm{~dB}$ between $700 \mathrm{~s}$ and $1000 \mathrm{~s}$, and high amplitude signals almost no longer appear. It indicates that the damage number decreases rapidly in the initial stage of load holding and the damage modes are matrix cracking and interface damage; however, the fiber breakage almost no longer occurs. In the middle stage of load holding (1000-10000 s), the level of signal incidence is low. The amplitude of signal is distributed between $55 \mathrm{~dB}$ and $80 \mathrm{~dB}$ from $1000 \mathrm{~s}$ to $10000 \mathrm{~s}$, and high amplitude signals rarely appear. It indicates that the damage in the composite is small and the major damage is matrix cracking and interface damage; however, the fiber breakage rarely occurs. In the later stage of load holding (after $10000 \mathrm{~s}$ ), the signal incidence reduces to the lowest level. The signal amplitude is less than $70 \mathrm{~dB}$ after $10000 \mathrm{~s}$, and the quantity of signal with the amplitude between $55 \mathrm{~dB}$ and $60 \mathrm{~dB}$ is more than that with the amplitude between $60 \mathrm{~dB}$ and $70 \mathrm{~dB}$. It indicates that the damage in composite decreases to the lowest level, the matrix cracking is the major damage, and none of fiber breakages occurs.

3.3. Criticality Analysis of Damage Modes in T700/6808 Composite. In the fiber reinforced epoxy resin matrix composite, the elastic modulus of fiber is about $235 \mathrm{Gpa}$; however, the elastic modulus of matrix is $4 \mathrm{Gpa}$ or lower. Therefore, $99 \%$ of strength of T700/6808 composite is undertaken by the fiber, and the damage of matrix also has great influence on the life of composite. Different damage modes will have various effects on the reliability of the material; in order to analyze the criticality of damage modes to the safety of T700/6808 composite, the criticality analysis was conducted on T700/6808 composite.

After the filtering of the AE signal with the amplitude between 55 and $70 \mathrm{~dB}$, the change of $\mathrm{AE}$ hit number with the tensile loading time for fiber breakage could be obtained as shown in Figure 7.

From Figure 7, it can be seen that the fiber breakage mainly occurs in the middle stage of tensile loading (60$580 \mathrm{~s}$ ), and the incidences of fiber breakage are different among three specimens during this period. In the later stage of tensile loading (580-700s), the incidence of fiber breakage decreases rapidly. When it comes into the stage of load holding (700-100000 s), the fiber breakage could be hardly found in the specimen of number 1 , and none of fiber breakages occurs in the specimen of number 2; however, the fiber breakage occurs occasionally in the specimen of number 3.

Figure 8 shows the change of cumulative number of fiber breakages with the tensile loading time in three specimens, obtained by the data processing in Figure 7 . 


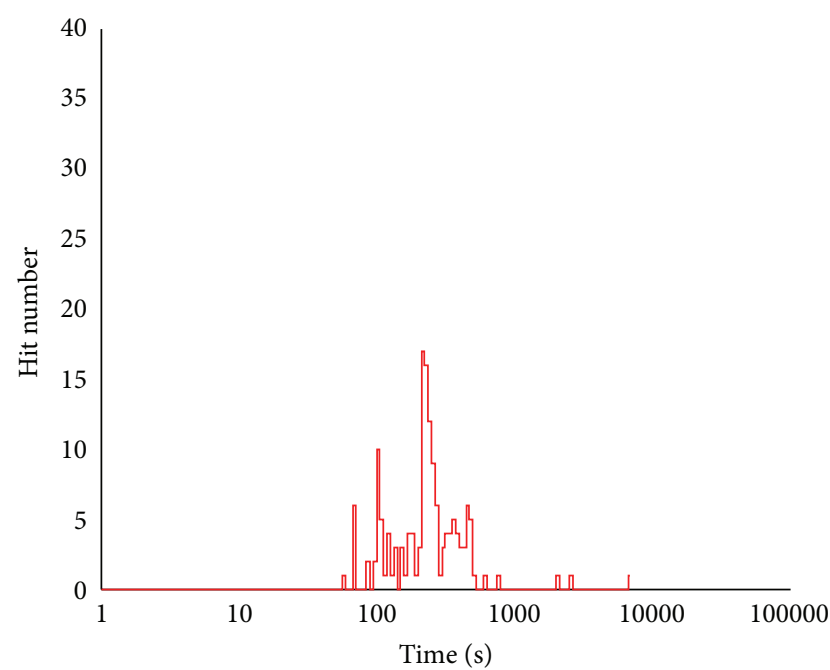

(a)

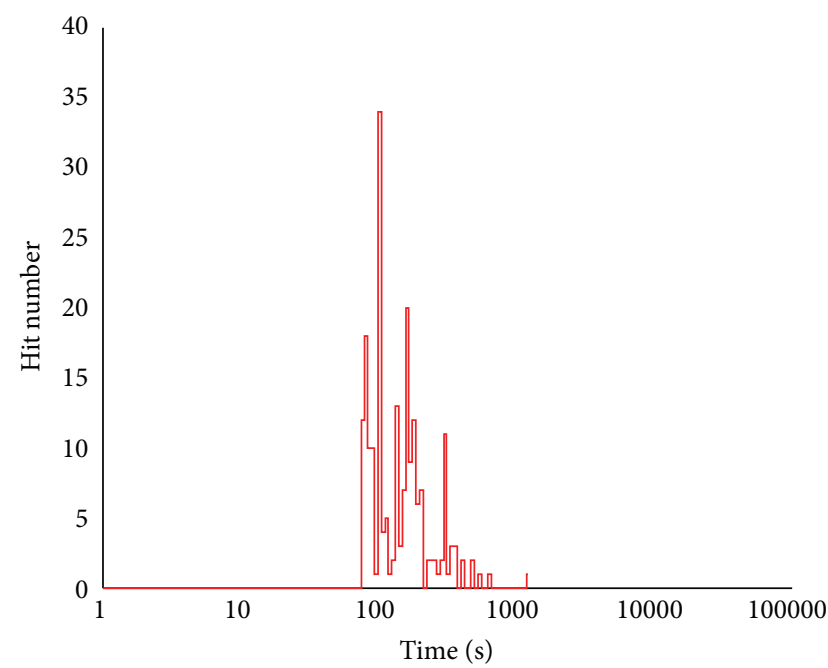

(b)

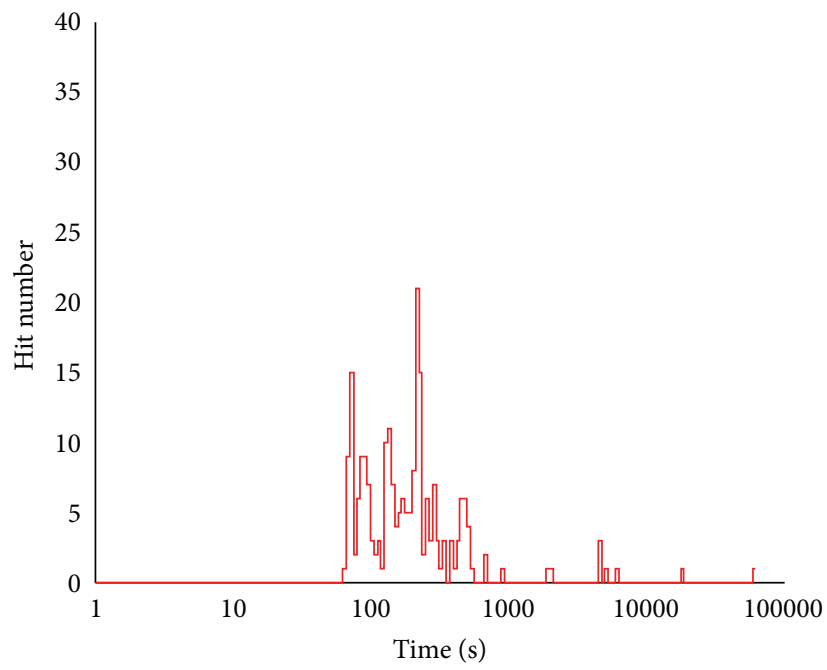

(c)

Figure 7: Change of AE hit number with the tensile loading time for fiber breakage in three specimens: (a) specimen of number 1; (b) specimen of number 2; (c) specimen of number 3.

As shown in Figure 8, fiber breakages nearly occur from $70 \mathrm{~s}$ to $700 \mathrm{~s}$ in all three specimens, and the number of fiber breakages becomes stable in the end of tensile loading at $700 \mathrm{~s}$.

In the load holding stage, the number of fiber breakages is, respectively, 4 in specimen of number 1, 2 in specimen of number 2, and 12 in specimen of number 3 . At the end of tensile testing, the cumulative numbers of fiber breakages are different among three specimens: the specimen of number 1 is 158 , the specimen of number 2 is 209 , and the specimen of number 3 is 223 . The number of fiber breakages and the damage process are different among three specimens, caused by the instability of forming technology and discreteness of fiber strength in the T700/6808 composite.

After the filtering of the AE signal with the amplitude between 71 and $100 \mathrm{~dB}$, the change of $\mathrm{AE}$ hit number with the tensile loading time for matrix and interface damage could be obtained as shown in Figure 9.
As shown in Figure 9, it can be seen that the damage of matrix and interface mainly occurs in the middle stage of tensile loading, and the incidences are different among three specimens. In the later stage of tensile loading, the incidence decreases rapidly, and the incidence is less than 100 when it comes into the load holding stage in most of specimens.

After the data processing in Figure 9, the change of cumulative damage number of matrix and interface with the tensile loading time is shown in Figure 10.

As shown in Figure 10, nearly all the damage of matrix and interface occurs from $60 \mathrm{~s}$ in three specimens. In the stage of tensile loading (0-700 s), the damage of matrix and interface has high incidence in three specimens, and the incidence reduces when the tensile loading finished. In the stage of load holding (after $700 \mathrm{~s}$ ), the curves of cumulative damage are parallel which indicates that the damage incidence is identical in the stage of load holding. At the end of the 


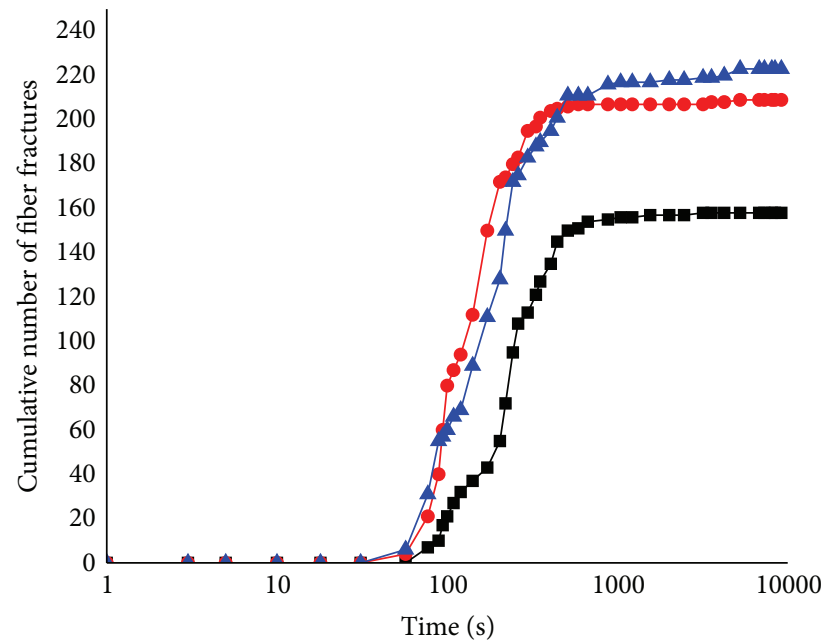

$\rightarrow$ Number 1

$\rightarrow$ Number 2

- - Number 3

FIGURE 8: Change of cumulative number of fiber breakages with the tensile loading time in three specimens.

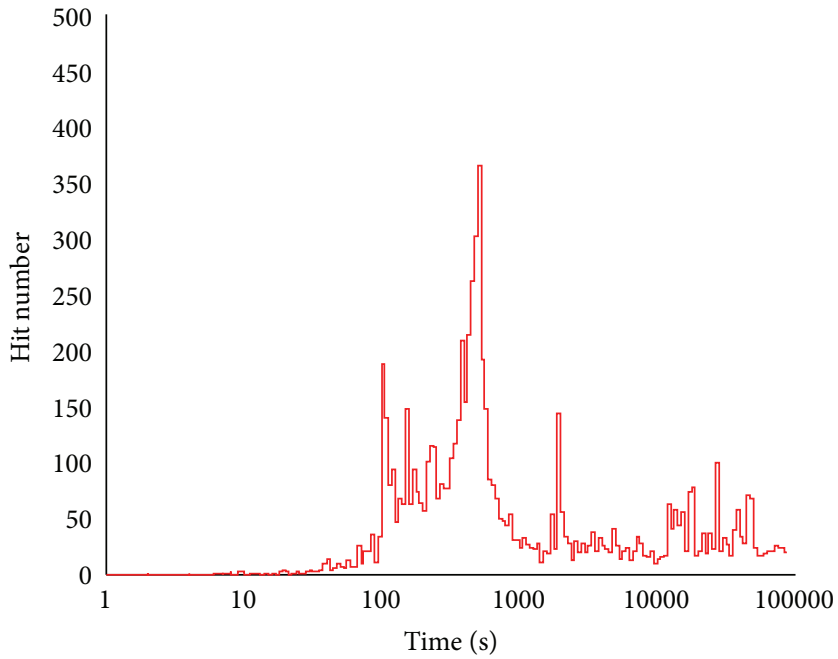

(a)

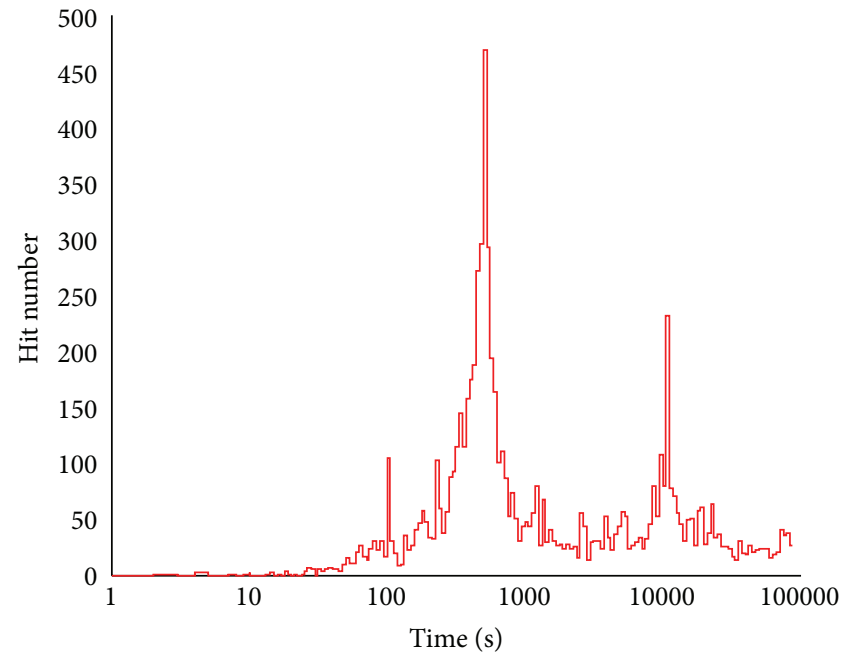

(b)

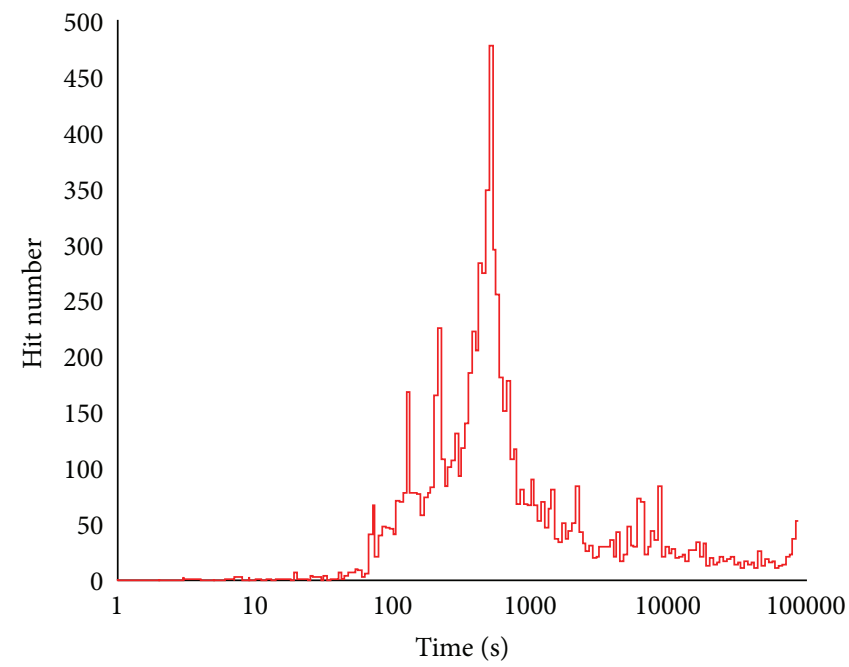

(c)

FIGURE 9: Change of AE hit number with the tensile loading time for matrix and interface damage in three specimens: (a) specimen of number 1 ; (b) specimen of number 2; (c) specimen of number 3. 


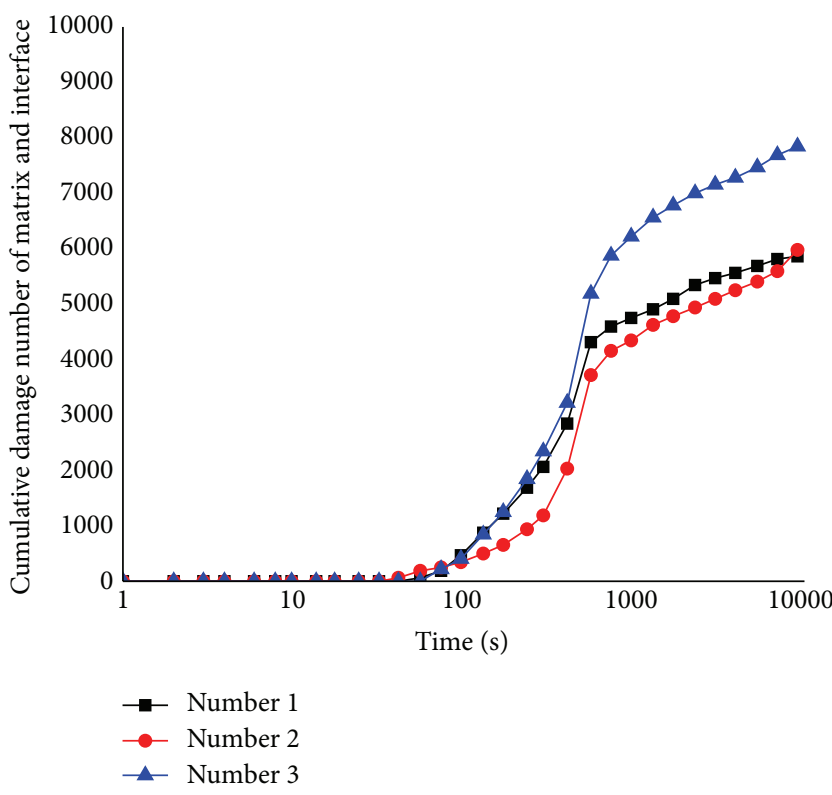

FIgURE 10: Change of cumulative damage number of matrix and interface with the tensile loading time.

tensile testing, it can be seen that the cumulative damage number of matrix and interface is, respectively, 5862 in specimen of number 1, 5977 in specimen of number 2, and 7844 in specimen of number 3 . The difference of cumulative damage number among three specimens shows the difference properties of matrix and interface, and it is mainly related to the discreteness of material molding process and the fiber breakage number.

From Figure 10, it can be seen that the cumulative damage number of matrix and interface is more than that of fiber, and the damage of matrix and interface still maintains high and stable incidence in the stage of load holding. The criticality of damage mode is the product of the incidence and damage duration, which illustrates that the matrix and the interface are the weakness affecting the reliability of T700/6808 composite.

\section{Discussion and Conclusions}

The study presents an investigation of damage evolution process in the T700/6808 composite based on AE technology, and some discoveries were obtained from the research. In the initial stage of tensile loading, due to the design bearing capacity of the material, small damage occurs inside the composite. The composite suffered from severe damage in the middle stage and the later stage of tensile loading, which mainly include the matrix cracking, the interface damage, and the fiber breakage. It is shown that the damage of T700/6808 composite mainly occurs in the stage of tensile loading.

The damage of T700/6808 composite had been decreased rapidly in the stage of load holding. The matrix cracking and interface damage are two major types of damage in T700/6808 composite; however, the fiber breakage rarely occurs. The fiber breakage mainly occurs in the middle stage of tensile loading; however, it seldom occurs in the later stage of tensile loading and load holding stage. It is shown that the fiber breakage of T700/6808 composite rarely occurs in the stage of load holding.

The maximum numbers of fiber breakage are different among three specimens, caused by the discreteness of fiber strength and the instability of forming technology of T700/6808 composite. The matrix cracking and interface damage have higher incidence and longer duration than the fiber in the whole process of tensile loading, which illustrates that the matrix and interface are the weakness affecting the reliability of T700/6808 composite.

\section{Competing Interests}

The authors declare no conflict of interests.

\section{Authors' Contributions}

Weihan Wang was responsible for drafting of paper; Weifang Zhang was responsible for designing of experiment; Shengwang Liu was responsible for conducting of experiment; Xiaoshuai Jin was responsible for analyzing of data.

\section{Acknowledgments}

This research is supported by two National Technical Infrastructure projects (the first is Project no. JSZL 2014610B001; the second is Project no. JSZL 2014601B004).

\section{References}

[1] M. Y. Liu and D. X. Liu, "Study on mechanical properties of T700/3234 laminate," Fiber Composites, vol. 1, pp. 16-19, 2013.

[2] B. Liu, Y. Yan, Z. X. Qi et al., "Tension property prediction and experiment study of T700 warp knitted fabric composite unidirectional laminates," in Proceedings of the 17th National Conference on Composite Material, pp. 783-788, Beijing, China, October 2012.

[3] A. Hase, H. Mishina, and M. Wada, "Fundamental study on early detection of seizure in journal bearing by using acoustic emission technique," Wear, vol. 346-347, pp. 132-139, 2016.

[4] B. C. Dykes, W. T. Hardrath, and D. S. Ulm, "An acoustic emission pre-failure warning system for composite structural tests," NASA Technical Reports A, vol. 93, pp. 175-181, 1992.

[5] H. X. Liu, Study on the damage and fracture of the composite flywheel by the acoustic emission method [M.S. thesis], Wuhan University of Technology, Wuhan, China, 2005.

[6] H. Y. Chou, A. P. Mouritz, M. K. Bannister, and A. R. Bunsell, "Acoustic emission analysis of composite pressure vessels under constant and cyclic pressure," Composites Part A: Applied Science and Manufacturing, vol. 70, pp. 111-120, 2015.

[7] S. K. Al-Jumaili, K. M. Holford, M. J. Eaton, and R. Pullin, "Parameter Correction Technique (PCT): a novel method for acoustic emission characterisation in large-scale composites," Composites Part B: Engineering, vol. 75, pp. 336-344, 2015.

[8] E. Maillet, N. Godin, M. R. Mili, P. Reynauda, G. Fantozzia, and J. Lamon, "Real-time evaluation of energy attenuation: a novel 
approach to acousticemission analysis for damage monitoring of ceramic matrix composite," Journal of the European Ceramic Society, vol. 34, no. 7, pp. 1673-1679, 2014.

[9] M. Saeedifar, M. Fotouhi, M. Ahmadi Najafabadi, and H. Hosseini Toudeshky, "Prediction of delamination growth in laminated composites using acoustic emission and Cohesive Zone Modeling techniques," Composite Structures, vol. 124, pp. 120-127, 2015

[10] L. S. Liu and G. W. Xia, "Technic research of apply acoustic emission in crack detection during composite rotor blades fatigue test," Heli Tech, vol. 1, pp. 35-38, 2003.

[11] S. Masmoudi, A. El Mahi, and R. El Guerjouma, "Mechanical behaviour and health monitoring by acoustic emission of sandwich composite integrated by piezoelectric implant," Composites Part B: Engineering, vol. 67, pp. 76-83, 2014.

[12] Y. Zhou, M. A. Baseer, H. Mahfuz, and S. Jeelani, "Statistical analysis on the fatigue strength distribution of T700 carbon fiber," Composites Science and Technology, vol. 66, no. 13, pp. 2100-2106, 2006.

[13] G. T. Zhang, W. G. Chen, B. Yang et al., "Testing research on mechanical properties of T700 carbon fiber/epoxy composites," Fiber Composite, vol. 2, pp. 49-52, 2009.

[14] J. Wang, X.-Q. Cheng, J.-K. Zhang, and Z.-N. Li, "Study on tension-tension fatigue properties of T700 composite laminates," Journal of Aeronautical Materials, vol. 32, no. 3, pp. 8590, 2012.

[15] L. N. S. Chiu, B. G. Falzon, D. Ruan et al., "Crush responses of composite cylinder under quasi-static and dynamic loading," Composite Structures, vol. 131, pp. 90-98, 2015.

[16] ASTM, "Standard test method for tensile properties of polymer matrix composite materials," ASTM D3039/D3039M-14, ASTM International, West Conshohocken, Pa, USA, 2010.

[17] P. F. Liu, J. K. Chu, Y. L. Liu, and J. Y. Zheng, "A study on the failure mechanisms of carbon fiber/epoxy composite laminates using acoustic emission," Materials and Design, vol. 37, pp. 228235, 2012.

[18] X. Zhuang and X. Yan, "Investigation of damage mechanisms in self-reinforced polyethylene composites by acoustic emission," Composites Science and Technology, vol. 66, no. 3-4, pp. 444449, 2006.

[19] S. Barré and M. L. Benzeggagh, "On the use of acoustic emission to investigate damage mechanisms in glass-fibre-reinforced polypropylene," Composites Science and Technology, vol. 52, no. 3, pp. 369-376, 1994. 


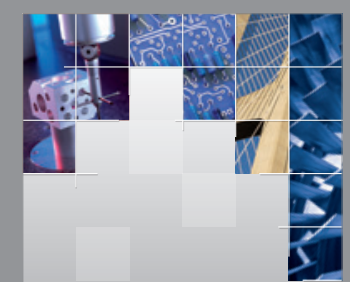

\section{Enfincering}
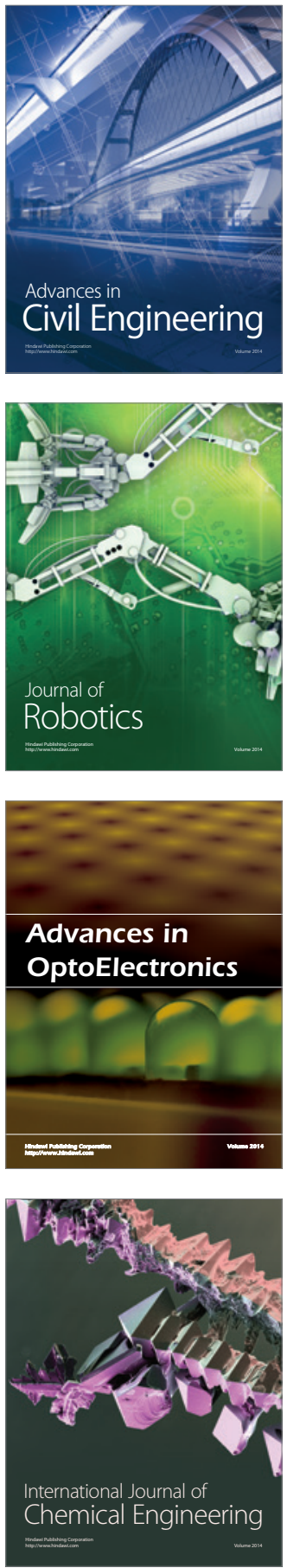

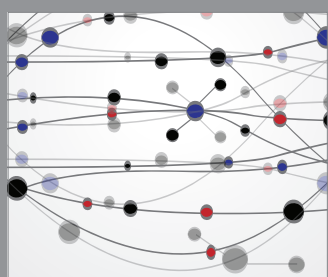

The Scientific World Journal

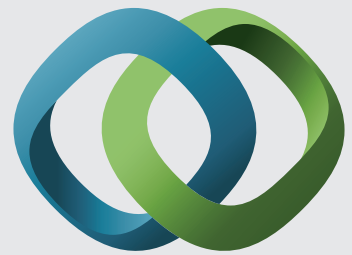

\section{Hindawi}

Submit your manuscripts at

http://www.hindawi.com
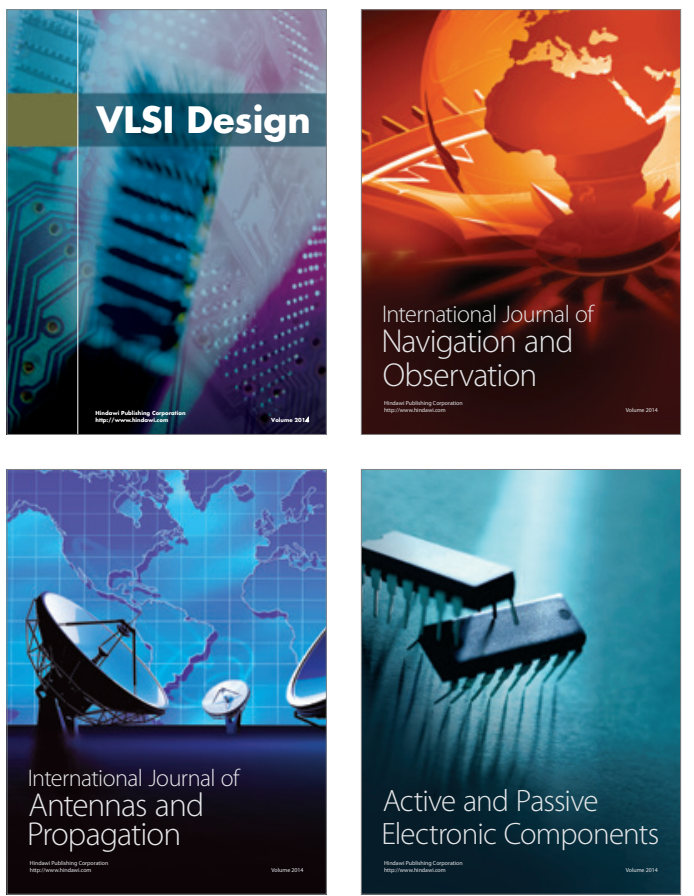
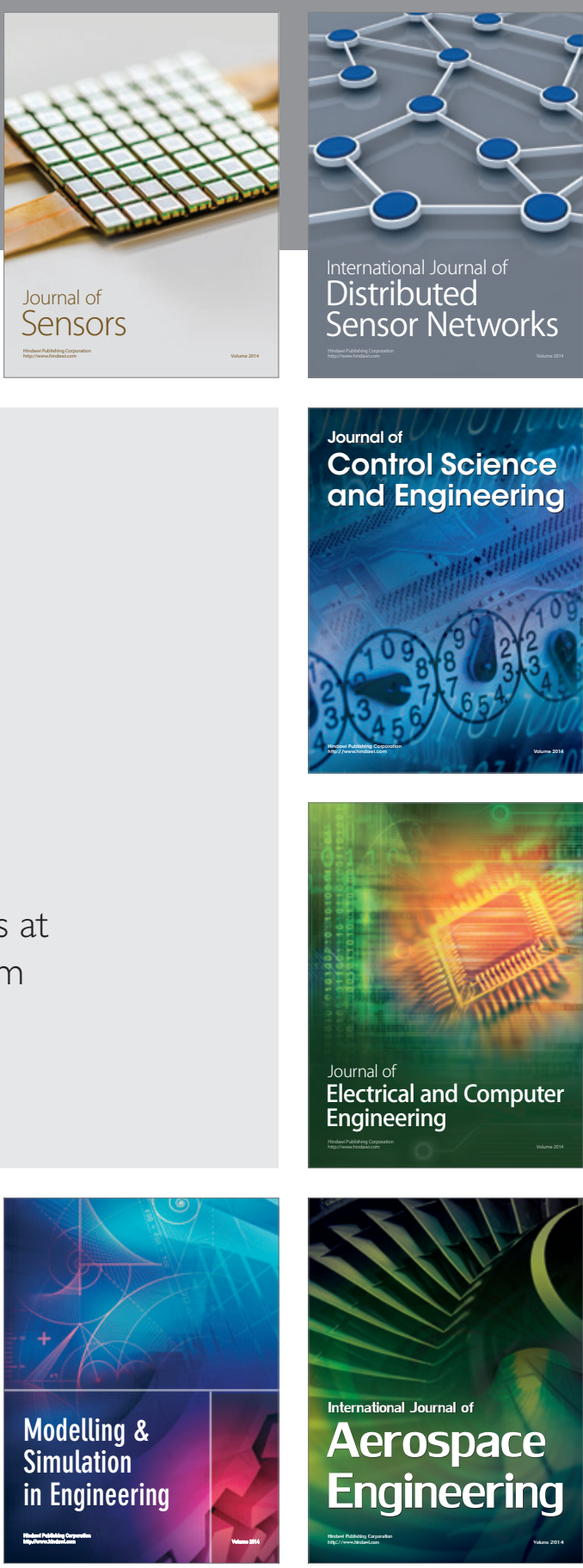

International Journal of

Distributed

Sensor Networks

Journal of

Control Science

and Engineering
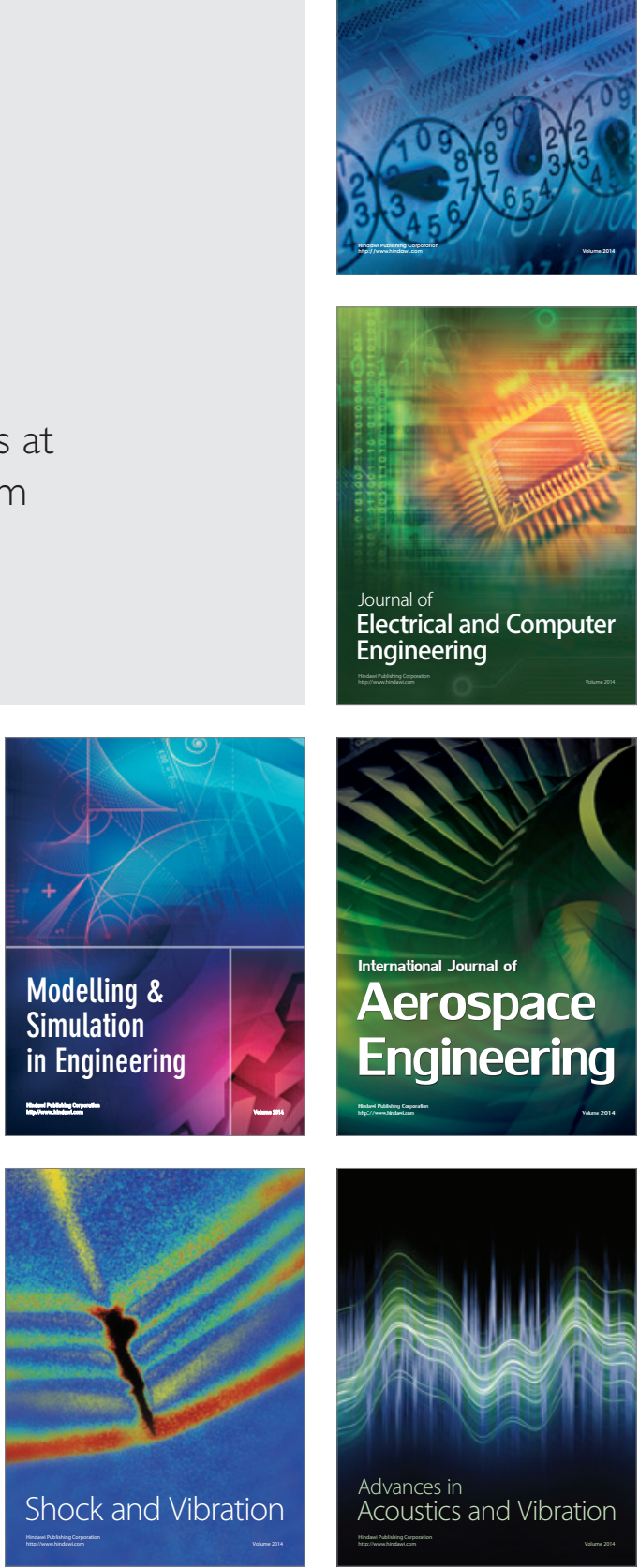